\title{
Researchers pin down risks of low-dose radiation
}

\section{Large study of nuclear workers shows that even tiny doses slightly boost risk of leukaemia.}

BY ALISON ABBOTT

$\mathrm{F}$ or decades, researchers have been trying to quantify the risks of very low doses of ionizing radiation — the kind that might be received from a medical scan, or from living within a few tens of kilometres of the damaged Fukushima nuclear reactors in Japan. So small are the effects on health - if they exist at all - that they seem barely possible to detect. A landmark international study has now provided the strongest support yet for the idea that longterm exposure to low-dose radiation increases the risk of leukaemia, although the rise is only minuscule (K. Leuraud et al. Lancet Haematol. http://doi.org/5s4; 2015).

The finding will not change existing guidelines on exposure limits for workers in the nuclear and medical industries, because those policies already assume that each additional exposure to low-dose radiation brings with it a slight increase in risk of cancer. But it scuppers the popular idea that there might be a threshold dose below which radiation is harmless - and provides scientists with some hard numbers to quantify the risks of everyday exposures.

"The health risk of low-dose radiation is really very tiny, but the public is very concerned," says Bill Morgan, who heads a systemsbiology programme in low-dose radiation at the Pacific Northwest National Laboratory in Richland, Washington, and chairs the committee on radiation effects at the International Commission on Radiological Protection (ICRP) in Ottawa, Canada. That concern has driven a lot of investment in programmes trying to quantify the risk, he says. The European Commission, for example, has a 20-year road map to assess the problem. "We don't do a very good job of explaining ourselves to the public, which finds it hard to put radiation risks in context - some people go to radon spas to treat their rheumatism while others won't board planes for fear of cosmic rays," he adds.

\section{RADIATION RISKS}

Ionizing radiation - the kind that can pull electrons from atoms and molecules and break DNA bonds - has long been known to raise the risks of cancer; the higher the accumulated dose, the greater the damage. But it has proved extremely difficult to determine whether this relationship holds at low doses, because any

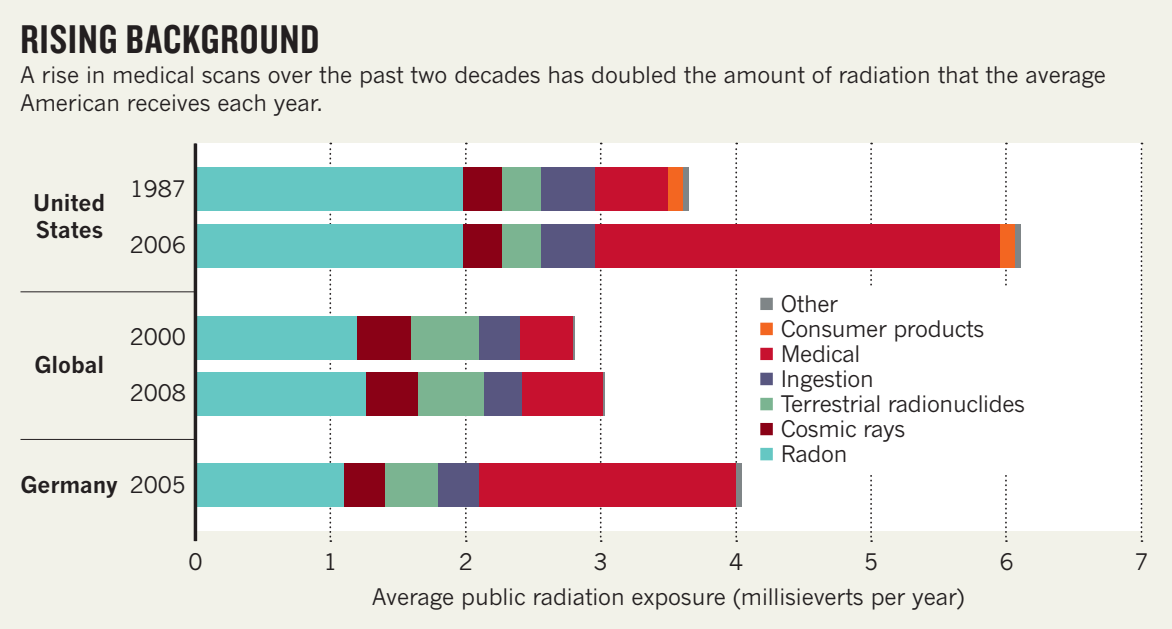

increase in risk is so small that to detect it requires studies of large numbers of people for whom the dose received is known. A study of more than 300,000 nuclear-industry workers in France, the United States and the United Kingdom, all of whom wore dosimeter badges, has provided exactly these data. A consortium of researchers coordinated by the International Agency for Research on Cancer (IARC) in Lyon, France, examined causes of death in the

\section{"The health} risk of lowdose radiation is really very tiny, but the public is very concerned." \section{workers (one-fifth of} whom had died by the time of the study) and correlated this with exposure records, some of which went back 60 years.

The workers received on average just 1.1 millisieverts ( $\mathrm{mSv}$ ) per year above background radiation, which itself is about 2-3 mSv per year from sources such as cosmic rays and radon. The study confirmed that the risk of leukaemia does rise proportionately with higher doses, but also showed that this linear relationship is present at extremely low levels of radiation. (Other blood cancers also tended to rise with radiation doses, but the associations were not statistically significant.) The results were published on 21 June.

"It is a solid, unusually large study of individuals exposed to very low doses of ionizing radiation," says epidemiologist Jørgen Olsen, director of the Danish Cancer Society Research Center in Copenhagen. The finding implies that some cases of leukaemia will even be caused by a high level of natural background radiation, he adds, "though the increased risk for an individual is going to be vanishingly small".

ICRP recommendations, which most national radiation-protection agencies follow, already call for monitoring of individuals whose annual exposure is likely to exceed $6 \mathrm{mSv}$. They restrict exposure to $20 \mathrm{mSv}$ annually over 5 years, with a maximum of $50 \mathrm{mSv}$ in any one year. Researchers found that 531 of the workers died from leukaemia during the average 27 years they spent in the industry; the data suggest that 30 of those deaths could be attributed to the radiation. Even in this large study, there was no direct evidence that workers who had accumulated extremely low doses of radiation (below a total of $50 \mathrm{mSv}$ ) had an increased risk of leukaemia, says Olsen. But a mathematical extrapolation of the data suggests that each accumulation of $10 \mathrm{mSv}$ of exposure raised a worker's risk of leukaemia by around 3\%, compared to the average risk of the group of workers in the study.

The data also challenge an ICRP assumption that accumulated low-dose exposure gives a lower risk of leukaemia than does a single exposure to the same total dose (based on the idea that the body has time to recover if the assault comes in tiny, spread-out doses). But such details are unlikely to change the overall ICRP recommendations, which are deliberately conservative, says Thomas Jung, from Germany's Federal Office for Radiation Protection in Munich. 


\section{- MEDICAL SCANS}

A major, and increasing, source of lowdose radiation comes from the medical world, says David Richardson, an epidemiologist at the University of North Carolina and an author of the study. "The amount of radiation a US person receives in a year on average has doubled, mostly because of medical procedures," he says (see 'Rising background'). Computed-tomography (CT) scans are to blame for most of the rise; a typical abdominal scan delivers more than $10 \mathrm{mSv}$. Radiologist David Brenner of Columbia University in New York has calculated that of the 25 million people having CT scans in a year, 1 million will have accumulated more than $250 \mathrm{mSv}$ over the previous 20 years.

One group that needs to pay particular attention to the findings are the tens of thousands of health workers who use radiological imaging to guide catheters through blood vessels of patients to reach into their hearts and brains, says Martha Linet, at the US National Cancer Institute's radiation epidemiology programme in Bethesda, Maryland. These minimally invasive operative procedures are used ever more frequently, she says.

Epidemiological studies suggest that radiation exposure has health effects beyond cancer. The IARC-led consortium is now looking at the effect on solid cancers, and also on diseases such as heart attack and stroke. Other studies are under way to study the long-term impact of low-dose radiation on different cohorts. One, the Epi-CT study, is recruiting one million people from nine European countries who had CT scans as children; its analysis will be complete by 2017 . In another, the Helmholtz Center Munich is analysing heart tissue from workers who died in the Mayak uranium mines in the South Urals, Russia.

Although the European Commission has been funding research on low-dose radiation for some time, equivalent programmes in the United States have stalled. In 2013, scientists wrote an open letter to the White House Office of Science and Technology Policy calling for renewed investment, and a bill is currently being debated in Congress calling for more work.

Getting funding for such studies is important, says Mike Atkinson, head of radiation biology at the Helmholtz Center Munich. Being able to quantify the effects of radiation will help doctors to balance risk against benefit when deciding whether to put children in CT scanners, he says. And further understanding the health impacts of low-dose radiation might aid decisions about how much remedial activity is needed to clean up soil contaminated by radioactivity from accidents or nuclear-power works, says Morgan. $\mathbf{\square}$

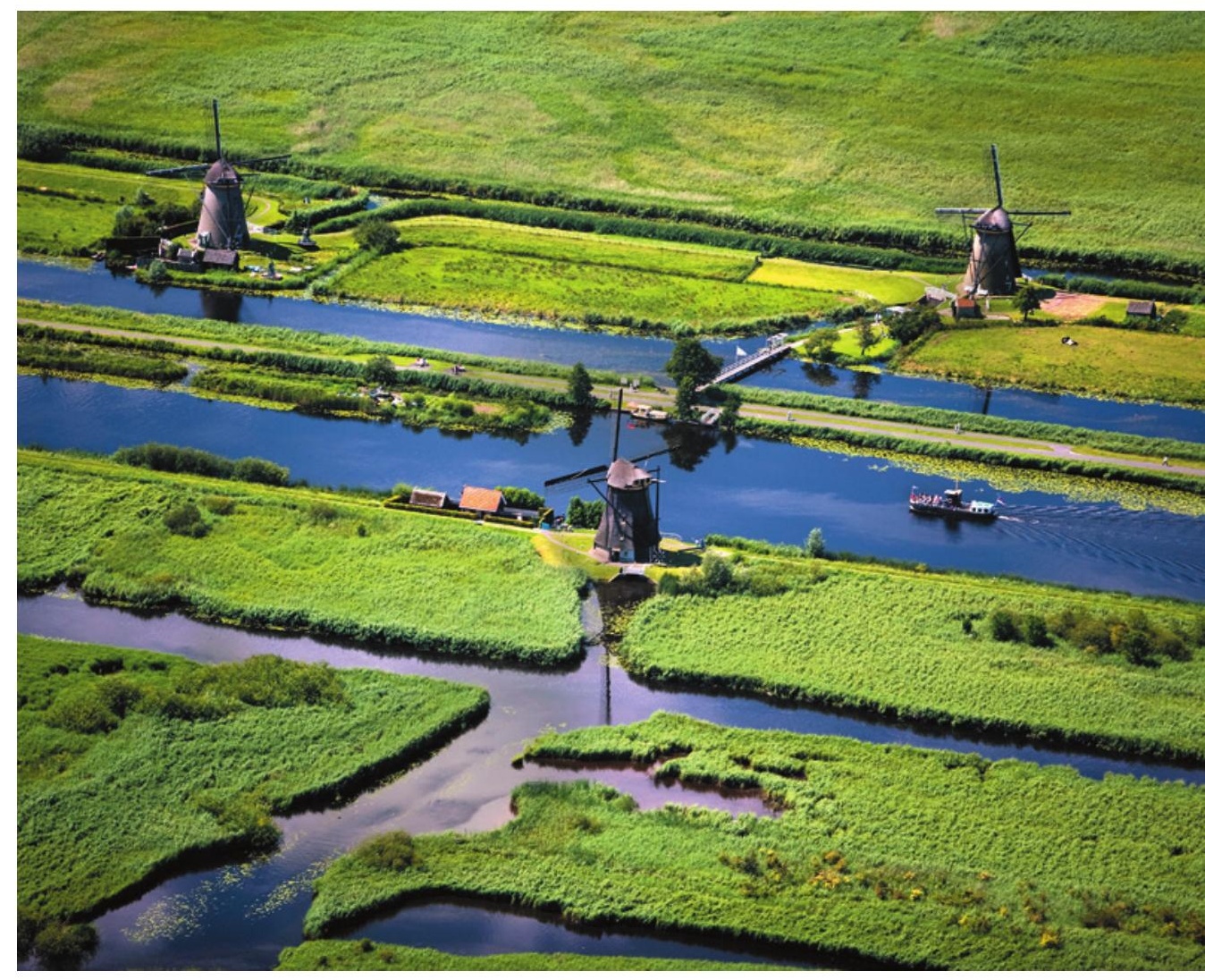

In the Netherlands, concerns about rising sea levels have led citizens to sue to force emissions cuts.

POLICY

\section{Courts weigh in on climate change}

\section{Successful Dutch climate litigation may encourage action across Europe, but US courts seem unlikely to follow suit.}

\section{BY QUIRIN SCHIERMEIER}

A group of Dutch citizens weary of ineffectual climate diplomacy are celebrating after forcing change through legal action. Last week, following a lawsuit filed by a citizens' climate-change platform called the Urgenda Foundation, a court in The Hague ordered the government of the Netherlands to cut greenhouse-gas emissions to at least 25\% below 1990 levels by 2020 - substantially greater cuts than are required under the small country's European Union (EU) obligations.

The ruling could encourage citizens of other countries to try using legal avenues to force stricter climate policies, says James Thornton, the London-based chief executive of Client Earth, an international group of environmental lawyers. "This is a very powerful decision with possible far-reaching repercussions," he says. "It is forcing the use of undisputed scientific results for responsible policy-making - a very remarkable step."

The Dutch government may still appeal the ruling, and even if it does have to implement extra emissions cuts, these would barely dent global greenhouse-gas emissions. But the court made clear that although Dutch policy-makers can do little to reduce emissions in China or the United States, they still have an obligation to act out of a duty of care for their citizens.

Thornton hopes that other courts will judge similar lawsuits in the same way in future. One such case is pending in Belgium, which must reduce its emissions by only $15 \%$ below 2005 levels under current EU pledges. But it is unclear whether the landmark Dutch ruling, and any European lawsuits that might follow, 